\title{
Effect of heat polymerization conditions and microwave on the flexural strength of polymethyl methacrylate
}

\author{
Serhat Emre Ozkir ${ }^{1}$, Burak Yilmaz $^{2}$, Server Mutluay Unal ${ }^{1}$, Ahmet Culhaoglu $^{3}$, \\ Isin Kurkcuoglu ${ }^{4}$
}

Correspondence: Dr. Burak Yilmaz

Email: yilmaz.16@osu.edu

\begin{abstract}
'Department of Prosthodontics, Faculty of Dentistry, Afyon Kocatepe University, Afyonkarahisar, Turkiye, 2Division of Restorative Sciences and Prosthodontics, College of Dentistry, The Ohio State University, Columbus, Ohio, USA, ${ }^{3}$ Department of Prosthodontics, Faculty of Dentistry, Kirikkale University, Kirikkale, Turkiye, ${ }^{4}$ Department of Prosthodontics, Faculty of Dentistry, Suleyman Demirel University, Isparta, Turkiye
\end{abstract}

\section{ABSTRACT}

Objective: The objective of this study is the effect of different heat polymerization conditions on the strength of polymethyl methacrylate (PMMA) resin base is unknown. Distinguishing one method that provides improved mechanical properties may be beneficial to the clinical success of complete and partial dentures and overdentures. The purpose of this study was to evaluate the effect of different polymerization methods on the flexural strength of a dental PMMA resin. Materials and Methods: Forty PMMA specimens $(64 \mathrm{~mm} \times 10 \mathrm{~mm} \times 4 \mathrm{~mm})$ were prepared with 4 different polymerization methods $(n=10)$; heat polymerization at $74^{\circ} \mathrm{C}$ for $9 \mathrm{~h}$, at $100^{\circ} \mathrm{C}$ for $40 \mathrm{~min}$, and with $620 \mathrm{kPa}$ pressure at $100^{\circ} \mathrm{C}$ for $20 \mathrm{~min}$. The remaining group of specimens was microwave polymerized at $180 \mathrm{~W}$ for 6 min. All specimens were thermocycled at $5^{\circ} \mathrm{C}$ and $55^{\circ} \mathrm{C}$ for 5000 times. Three-point flexure test was used to measure the flexural strength of specimens. One-way ANOVA and Tukey Honestly Significant Difference were applied to analyze the differences in flexural strengths $(\alpha=0.05)$. Results: The flexural strength of heat-polymerized groups was similar. The flexural strength of microwave polymerized group was significantly different and lower than the other groups $(P<0.05)$. Conclusion: Polymerizing conventional heat-polymerizing PMMA resin with microwave energy resulted in a significant decrease in flexural strength. The results of this study suggest that clinicians may benefit from using heat polymerization when processing PMMA denture bases instead of microvawe polymerization when tested brand is used.

Key words: Flexural strength, microwave, polymethyl methacrylate, polymerization

\section{INTRODUCTION}

Polymethyl methacrylate (PMMA) has been the most common denture base material for decades. ${ }^{[1-3]}$ Various types of acrylic resins and polymerization techniques

\begin{tabular}{|l|l|}
\hline \multicolumn{2}{|c|}{ Access this article online } \\
\hline Quick Response Code: \\
\hline
\end{tabular}

have been developed and introduced to improve the physical and mechanical characteristics. ${ }^{[4-6]}$ PMMA

This is an open access article distributed under the terms of the Creative Commons Attribution-NonCommercial-ShareAlike 3.0 License, which allows others to remix, tweak, and build upon the work non-commercially, as long as the author is credited and the new creations are licensed under the identical terms.

For reprints contact: reprints@medknow.com

How to cite this article: Ozkir SE, Yilmaz B, Unal SM, Culhaoglu A, Kurkcuoglu I. Effect of heat polymerization conditions and microwave on the flexural strength of polymethyl methacrylate. Eur $\mathrm{J}$ Dent 2018;12:116-9.

DOI: 10.4103/ejd.ejd_199_17 
can be polymerized using different methods such as heat, light, and microwave energy..$^{[4,6]}$ The aim of using different processing methods have been to simplify the technique and reduce the processing time. ${ }^{[1]}$ The conventional method for polymerizing PMMA is the hot water bath; however, there are also many submethods of this procedure such as low temperature-long duration $\left(74^{\circ} \mathrm{C}, 9 \mathrm{~h}\right)$ or high temperature-short duration $\left(100^{\circ} \mathrm{C}, 20 \mathrm{~min}\right)$. During polymerization with the increase of heat, polymer formation and conversion of monomer into polymer increase. On the other hand, the reduction in temperature may lead to a decrease of polymer formation and an increased amount of residual monomer in the resin. ${ }^{[4,7]}$

The amount of residual monomer can be affected by changes in time, temperature, and the polymerization method. ${ }^{[7]}$ The increased amount of residual monomer has adverse effects on the physical and mechanical properties of PMMA. ${ }^{[5,7]}$

Microwave polymerization method was introduced in 1968 and it became a popular alternative to hot water-bath polymerization method. ${ }^{[2,5]}$ Several advantages with this method have been reported; shorter processing times, a cleaner process, and superior adaptation to the cast. ${ }^{[8,9]}$ Besides, it was reported that the microwave-polymerized resin had reduced amount of residual monomer. ${ }^{[7]}$

The logic of microwave polymerization is the rapid acceleration of molecules in a high-frequency electromagnetic field, and the heat increase can be obtained by the intermolecular collisions. The heating occurs quicker within the material homogenously, thus, the time to transfer the heat from the outer sources to the resin is not needed. ${ }^{[7]}$ However, there are some drawbacks of microwave polymerization method. Overheating and the rapid heating of the monomer should be avoided as it may vaporize and cause porosity, which was also reported when the microwave polymerization was used with conventional PMMA resins. ${ }^{[9]}$ Various PMMA resins manufactured for microwave polymerization are commercially available.

A material's flexural strength gives an idea about its resistance to fracture. ${ }^{[7]}$ The flexural strength of PMMA is small and important for its clinical success. ${ }^{[10]}$ The strength of PMMA is particularly important when implant-supported overdentures are fabricated as fractures have been commonly reported in the literature with these dentures. ${ }^{[11]}$ In previous studies, different brands and types of PMMA resins were tested and compared with each other. However, to the authors' knowledge, there is no comparison of the effect of polymerization method on a commercially available conventional PMMA. The aim of this study was to investigate the effect of different polymerization methods on the flexural strength of PMMA. The null hypothesis was that the polymerization method would not affect the flexural strength of the PMMA resin.

\section{MATERIALS AND METHODS}

Forty PMMA specimens $(64 \mathrm{~mm} \times 10 \mathrm{~mm} \times 2.5 \mathrm{~mm})$ were prepared. Heat-polymerized PMMA resin (Meliodent Heat Cure, Heraeus Kulzer) was mixed at a room temperature $\left(22^{\circ} \mathrm{C}\right)$ in accordance with the manufacturers' instructions. The specimen groups that were heat polymerized in hot water bath were packed into stone molds and brass flasks. The packed specimens were divided into 3 groups $(n=10)$ and polymerized at $74^{\circ} \mathrm{C}$ for $9 \mathrm{~h}$, at $100^{\circ} \mathrm{C}$ for $40 \mathrm{~min}$ in a polymerization tank (MD-135, Meta), and under $620 \mathrm{kPa}$ pressure at $100^{\circ} \mathrm{C}$ for $20 \mathrm{~min}$ in a pressure chamber (Polimer 180, Zhermack) under water. The remaining 10 specimens were prepared with the same way but packed into FRP (GC) for microwave polymerization. These specimens were polymerized at 180 watt for 6 min in a microwave oven (MD 890, Arcelik). The microwave oven used in the study had a power source of $220 \mathrm{~V}, 50 \mathrm{MHz}$, and a maximum power output of $800 \mathrm{~W}$. The power output can be adjusted to six settings of $20 \%, 40 \%, 60 \%, 80 \%$, and $100 \%$ of total maximum power. Time control can be adjusted between $10 \mathrm{~s}$ and $75 \mathrm{~min}$. The optimum power and timing were estimated by preliminary experiments and set as $40 \%$ power for $6 \mathrm{~min}$.

After the polymerization of resins, the excess material was removed with a tungsten carbide bur (Euro Carbide Bur; Dedeco) at 15.000 rpm, and the surfaces were finished with 200 and 600 grid sandpapers. The specimens were thermocycled at $5^{\circ} \mathrm{C}$ and $55^{\circ} \mathrm{C}$ for 5000 times (Esetron). ${ }^{[10]}$ The cycle periods were $15 \mathrm{~s}$ for hot and cold water and $30 \mathrm{~s}$ of dwell time.

Three-point flexure test (ISO 1567) was used to measure the flexural strength of the specimens. The specimens were placed in a test machine (Esetron) on a test rig with cylindrical supports which were $3.2 \mathrm{~mm}$ in diameter and $50 \mathrm{~mm}$ apart. The load was applied on the specimens at a crosshead speed 
of $5 \mathrm{~mm} / \mathrm{min}$. The fracture force was recorded in newton $(\mathrm{N})$ and flexural strength $\left(\mathrm{F}_{\mathrm{s}}\right)$ was calculated with the formula:

$\mathrm{F}_{\mathrm{s}}=3 \mathrm{PL} / 2 \mathrm{bd}^{2}$

Where $\mathrm{P}$ is maximum load, $\mathrm{L}$ is span length, $\mathrm{b}$ is specimen width, and $\mathrm{d}$ is specimen thickness. ${ }^{[10]}$

Statistical analysis was conducted using software (SPSS for Windows V19). Flexural strength was analyzed using Kruskal-Wallis with post hoc Tukey Honestly Significant Difference test. Iman Conover pairwise comparison test was used to detect the differences among the groups. All tests used were at 0.05 level of statistical significance.

\section{RESULTS}

The mean flexural strength values of tested PMMA groups are displayed in Figure 1. The Kruskal-Wallis test showed that there were significant differences among the groups regarding flexural strength $(P<0.05)$ and Iman Conover pairwise comparison test showed that the microwave-polymerized PMMA group was significantly different from the heat-polymerized groups, while the heat-polymerized groups did not have significant differences among each other [Table 1].

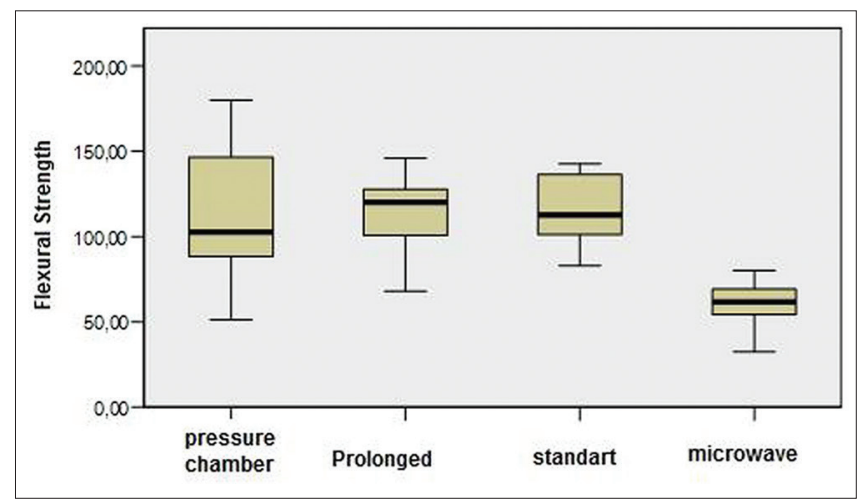

Figure 1: Flexural strength of polymerized resins using different techniques. The error bars show standard deviations

\begin{tabular}{|c|c|c|}
\hline Polymerization method & Mean (MPa) & SD \\
\hline \multicolumn{3}{|l|}{ Heat-polymerized } \\
\hline Under pressure & $110.46^{a}$ & 39.10 \\
\hline Prolonged & $114.6^{a}$ & 24.40 \\
\hline Standard & $114.92^{\mathrm{a}}$ & 20.19 \\
\hline Microwave & $60.33^{b}$ & 13.10 \\
\hline
\end{tabular}

\section{DISCUSSION}

The null hypothesis of this study was partially rejected because the microwave polymerized specimens' flexural strength was significantly lower than that of heat polymerized while water bath polymerization did not have statistically different effects on the flexural strength of PMMA. One of the common reasons for clinical failure of the denture base resins is the flexural failure ${ }^{[1]}$ Many modifications have been made since the PMMA was first used and different polymerization techniques were also developed. ${ }^{[4,5]}$ To examine and compare the denture resins, three-point bending test is valuable as it simulates the forces loaded on the resins during mastication. ${ }^{[1]}$

According to ISO 15671, the minimum value of flexural strength for heat-polymerized and microwave polymerized resins should not be lower than $65 \mathrm{MPa} .^{[7]}$ The polymerization technique or cycles were reported to be effective on the strength of PMMA resin. ${ }^{[4]}$ In the current study, the conventional water bath heat polymerization methods' flexural strength values were above the minimum strength value stated in ISO standards. However, microwave polymerized specimens' were below this level. Although there were not statistically significant differences among the conventional water bath polymerized specimens, it could be seen that there was a tendency of flexural strength to increase with the extended polymerization time.

There are several studies which compared polymerization cycles and methods in the literature. ${ }^{[1,3,4]}$ Barbosaetal.and Murakamietal.reported thatmicrowave polymerized resins showed higher flexural strength than the conventional heat-polymerized resins, while Consani et al. reported no differences for polymerization cycle-resin interaction. ${ }^{[1,3,4]}$ However, they also stated that by changing the polymerization method of a high-impact heat-polymerized resin, the mechanical and physical properties were affected. In addition, slow polymerization positively affects the properties of the resin. ${ }^{[4]}$ In another study by Murakami et al., it was stated that polymerization under high pressure $(500 \mathrm{MPa})$ increases the mechanical properties of the resin as high pressure application on monomer decreased the intermolecular distances. ${ }^{[3]}$ In the current study, the polymerization was established with the initial pressure applied before heat application except one group which was polymerized in a pressure chamber applying $620 \mathrm{kPa}$ pressure. Although the flexural strength of this group was well above the 
minimum ISO standards and was not significantly different, the flexural strength values were below other heat polymerized PMMA groups. This may be because of the shorter time of heat application on the specimens. Three methods used in this study were all suitable for polymerization according to the outcomes of the flexural strength tests.

Microwave energy has been used for polymerization of PMMA resin as an alternative to the conventional heat polymerization. Shorter polymerization time and cleaner processing were the leading advantages of this method. ${ }^{[8,9]}$ However, there are conflicting results regarding the flexural strength of this material in the literature. While some researches stated that the microwave polymerization caused a decrease in flexural strength, the others stated no significant difference of flexural strength between the microwave polymerized and heat polymerized resins..$^{[1,4,5,7,8]}$

One of the common problems of polymerizing a conventional PMMA resin with microwave energy is the porosity in the resin. Porosity affects the flexural strength of the material as well as promoting bacterial accumalation and causing esthetic problems. Heat-polymerized PMMA monomer vaporizes beyond $100.3^{\circ} \mathrm{C}$ which causes porosity within the resin. ${ }^{[6]}$ However, the conversion of monomer into polymers under $100^{\circ} \mathrm{C}$ would require prolonged time which would be impractical. ${ }^{[7]}$ Although it was also reported that conventional heat polymerized resins can be used with the microwave method, in the current study, the microwave polymerized resins showed high porosity in line with the previous studies. ${ }^{[6,9,12]}$ This result showed that the high vapor pressure of the PMMA boils and vaporizes during microwave polymerization and it would be more suitable to use microwave monomers with dimethacrylates which have low vapor pressure even at $150^{\circ} \mathrm{C} .{ }^{[6]}$ It was also reported that at elevated temperatures such as $150^{\circ} \mathrm{C}$ polymerizing PMMA without porosities was impossible. ${ }^{[7]}$ In the current study, polymerizing a conventional PMMA with microwave energy resulted in unfavorable flexural strength and porosity. It was also reported that the monomers formulated for microwave polymerization did not show significant differences than the conventional heat polymerized PMMA for porosity. ${ }^{[7,9]}$ The power of the microwave and duration should be carefully determined..$^{[1,3]}$

This was an in vitro study with only one acrylic resin brand tested. However, there are several commercially available PMMA resins with various copolymer compositions. The change of the chemical properties of the resin may affect the mechanical properties. Future studies should be conducted to test different brands using similar methods. Clinical studies can be helpful to see the effect of the polymerization method on the long-term clinical success of acrylic resin-based dentures.

\section{CONCLUSION}

Within the limitations of this study, the following conclusions may be drawn:

1. The flexural strength of PMMA groups which were heat-polymerized using different methods was similar

2. Polymerizing conventional heat-polymerizing PMMA resin with microwave energy resulted in a decrease in flexural strength.

\section{Financial support and sponsorship}

Nil.

\section{Conflicts of interest}

There are no conflicts of interest.

\section{REFERENCES}

1. Barbosa DB, de Souza RF, Pero AC, Marra J, Compagnoni MA. Flexural strength of acrylic resins polymerized by different cycles. J Appl Oral Sci 2007;15:424-8.

2. Sahin O, Ozdemir AK, Turgut M, Boztug A, Sumer Z. Investigation of flexural strength and cytotoxicity of acrylic resin copolymers by using different polymerization methods. J Adv Prosthodont 2015;7:98-107.

3. Murakami N, Wakabayashi N, Matsushima R, Kishida A, Igarashi Y. Effect of high-pressure polymerization on mechanical properties of PMMA denture base resin. J Mech Behav Biomed Mater 2013;20:98-104.

4. Consani RL, Folli BL, Nogueira MC, Correr AB, Mesquita MF. Effect of polymerization cycles on gloss, roughness, hardness and impact strength of acrylic resins. Braz Dent J 2016;27:176-80.

5. Azzarri MJ, Cortizo MS, Alessandrini JL. Effect of the curing conditions on the properties of an acrylic denture base resin microwave-polymerised. J Dent 2003;31:463-8.

6. Singh S, Palaskar JN, Mittal S. Comparative evaluation of surface porosities in conventional heat polymerized acrylic resin cured by water bath and microwave energy with microwavable acrylic resin cured by microwave energy. Contemp Clin Dent 2013;4:147-51.

7. Spartalis GK, Cappelletti LK, Schoeffel AC, Michél MD, Pegoraro TA, Arrais CA, et al. Effect of conventional water-bath and experimental microwave polymerization cycles on the flexural properties of denture base acrylic resins. Dent Mater J 2015;34:623-8.

8. Madan G, Madan S, Madan G. Comparison of polymethyl methacrylate curing by conventional hot-water bath and microwave energy. Int J Dent Clin 2014;6:10-3.

9. Compagnoni MA, Barbosa DB, de Souza RF, Pero AC. The effect of polymerization cycles on porosity of microwave-processed denture base resin. J Prosthet Dent 2004;91:281-5.

10. Fonseca RB, Kasuya AV, Favarão IN, Naves LZ, Hoeppner MG. The influence of polymerization type and reinforcement method on flexural strength of acrylic resin. ScientificWorldJournal 2015;2015:919142.

11. Gonda T, Maeda Y, Walton JN, MacEntee MI. Fracture incidence in mandibular overdentures retained by one or two implants. J Prosthet Dent 2010;103:178-81.

12. Ilbay SG, Güvener S, Alkumru HN. Processing dentures using a microwave technique. J Oral Rehabil 1994;21:103-9. 